\title{
Dithioacetals as Zwitterion Synthons
}

\author{
Tien-Yau Luh,*[a] and Chin-Fa Lee ${ }^{[a]}$
}

Keywords: Propargylic dithioacetals / Zwitterion synthons / Furans / Pyrroles / Oligoaryls

This microreview highlights recent advances in the synthetic applications of dithioacetal functionality. Propargylic dithioacetals and related compounds have been shown to be useful, with the aid of thiophilic organolithium or organocopper reagents, for the synthesis of polysubstituted allenes, trisubstituted furans, and pyrroles. An extension of this annulation reaction to the bidirectional iterative synthesis of furan-containing oligoaryls and to cyclophane synthesis is described. Alternatively, the convergent synthesis of such oli- goaryls from propargylic dithioacetals is briefly discussed. Not only can the carbon-sulfur bonds in dithioacetals be readily displaced by carbon-carbon and/or carbon-heteroatom bonds, but in addition a range of reactions involving polarity inversion in neighboring carbon atoms can also take place.

() Wiley-VCH Verlag GmbH \& Co. KGaA, 69451 Weinheim, Germany, 2005)

\section{Introduction}

Carbon (2.50) and sulfur (2.44) atoms have similar electronegativities. This characteristic may be reflected in the ambiphilic reactivity of the carbon-sulfur bond. The sulfur moiety in a thioether can thus serve as a sulfide leaving group ${ }^{[1]}$ In this case, the thioether group is occasionally activated by an electrophile so that the displacement reaction

[a] Department of Chemistry, National Taiwan University,

Taipei, Taiwan 106

Fax: +886-2-2364-4971

E-mail: tyluh@ntu.edu.tw can readily occur [Equation (1)].[1] Nickel-catalyzed cross coupling reactions of $\mathrm{sp}^{2}$-hybridized carbon-sulfur bonds furnish an alternative route resulting in carbon-carbon bond formation [Equation (2)], the thioether moiety here being interpretable as a carbocation synthon. ${ }^{[2-4]}$

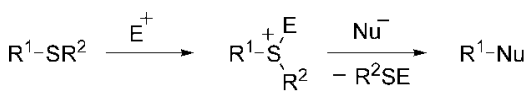

$=\mathrm{SR}^{1} \frac{\mathrm{R}^{2} \mathrm{MgX}}{\mathrm{NiCl}_{2} \text { (phosphane) }}=\mathrm{R}^{2}$

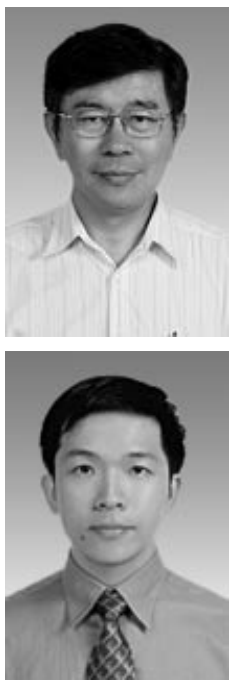

Tien-Yau Luh obtained his Ph.D. degree from the University of Chicago (with L. M. Stock) in 1974. After spending two years of postdoctoral research at the University of Minnesota (with P. G. Gassman), he joined the Chinese University of Hong Kong in 1976 and moved back in 1988 to his alma mater, National Taiwan University, where he is Professor of Chemistry. He has published more than 200 papers and has received numerous awards in Taiwan. His international publishing activities include serving on the boards of Chemistry - A European Journal, Journal of Organometallic Chemistry and Bulletin of the Chemical Society of Japan. His current research interests include OMCOS, synthesis of regioregular polymers for optoelectronic interests, and the chemistry of materials.

Chin-Fa Lee was born in 1975 and obtained his Ph.D. degree from the National Taiwan University in 2002 (with T.- Y. Luh). After spending one postdoctoral year each with T.-Y. Luh at NTU and with J. F. Hartwig at Yale, he is now working with D. A. Leigh at Edinburgh University as a postdoctoral associate. During his graduate study at the NTU he discovered the furan annulation reaction described in this microreview. His research interests include homogeneous catalysis, chemistry of optoelectronic materials, and self-assembly chemistry.

MICROREVIEWS: This feature introduces the readers to the authors' research through a concise overview of the selected topic. Reference to important work from others in the field is included. 
Alternatively, the sulfur end can be regarded as an electrophile, the most prominent example being the reactions between thiocarbonyl groups and Grignard reagents or alkyllithiums [Equation (3)]. ${ }^{[5]}$ The nucleophile adds onto the sulfur end, resulting in the formation of a carbanion, which can further react with an electrophile to give the corresponding product. In general, the carbanion is stabilized by the presence of another conjugated moiety or hetero$\operatorname{atom}(\mathrm{s})$.

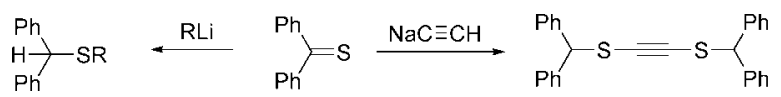

Similarly, the reaction between a thioether bond and an organometallic reagent will generate a carbanionic leaving group. The driving force for such a reaction may arise from release of steric or ring strain, ${ }^{[6,7]}$ or the anionic species may be stabilized by other substituents [Equation (4), Equation (5)]. ${ }^{[8,9]}$ Treatment of sulfur-containing heteroaromatics [Equation (6), Equation (7) $]^{[10-14]}$ or alkynyl thioethers ${ }^{[15]}$ with organolithium reagents results in the cleavage of the $\mathrm{C}-\mathrm{S}$ bond.
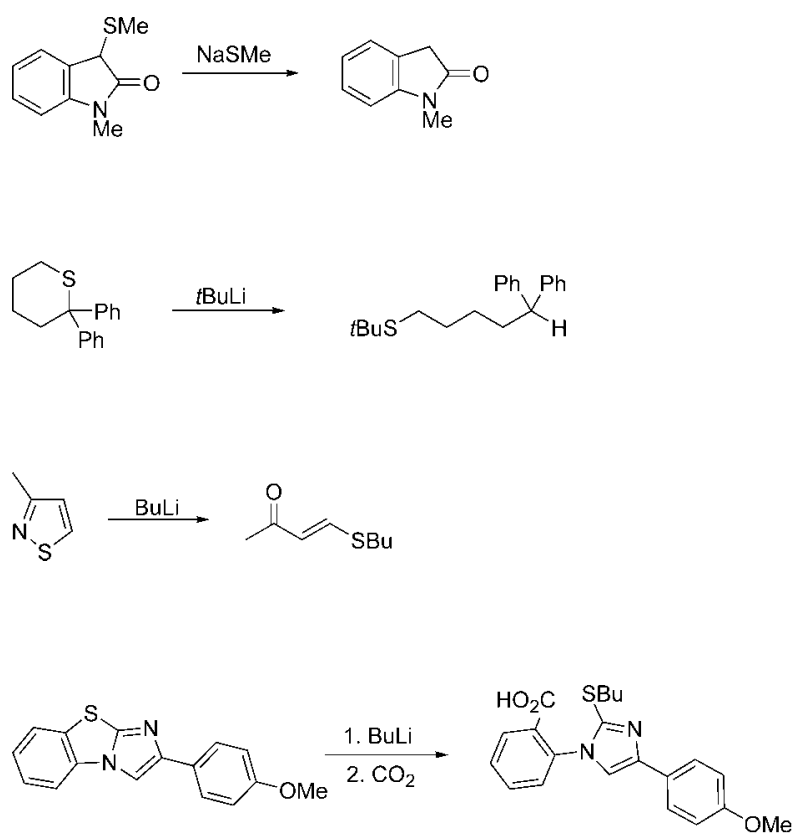

A dithioacetal has two geminal carbon-sulfur bonds. The most frequent usage of this functional group has been restricted to its serving as a latent carbonyl ${ }^{[16]}$ or methylene group. ${ }^{[17]}$ Although the well known use of 2-lithio-1,3-dithiane as a carbonyl anion synthon is fascinating, ${ }^{[18]}$ dithiacetal chemistry is still quite limited. Selective displacements of these two bonds by carbon-carbon bonds can be useful in organic synthesis. Earlier works on the reactions involving conversion of the two carbon-sulfur bonds into carbon-carbon bonds have been reviewed. ${ }^{[19-23]}$ In these cases, the dithioacetal moiety can be regarded as a dication synthon or a carbene synthon (Scheme 1).

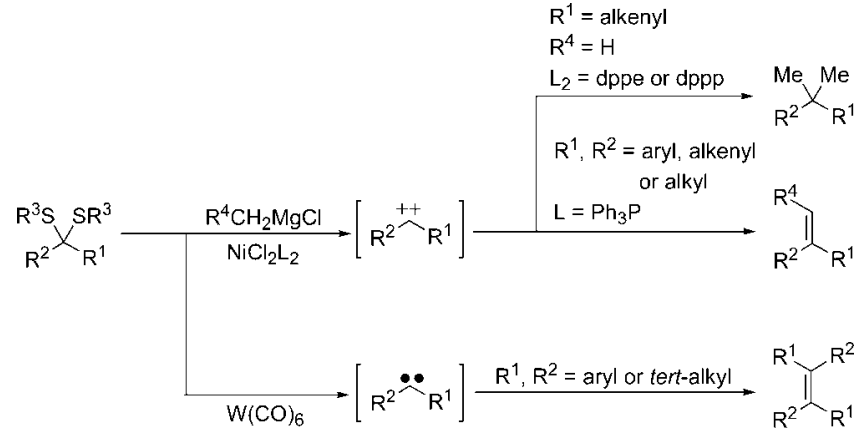

Scheme 1.

The dithioacetal functionality can be viewed as a special kind of thioether. Several sites in the dithioacetal group are known to react with alkyllithiums. Other than the generation of 2-lithio-1,3-dithiane just mentioned, ${ }^{[18]}$ the reaction behavior of five-membered 1,3-dithiolanes is much more complicated. Deprotonation at $\mathrm{C}_{2}$ or $\mathrm{C}_{4}$ has been shown to result in fragmentation of five-membered heterocycles. ${ }^{[24,25]}$ Nevertheless, benzylic dithioacetals react chemoselectively with organolithium, resulting in the formation of the corresponding sulfur- and aryl-stabilized carbanions, which are quenched with an electrophile to afford the corresponding thioethers [Equation (8)]. ${ }^{[26]}$ Organocopper reagents behave similarly [Equation (9)]. ${ }^{[27]}$ More recently, an extension of this reaction to allylic and propargylic dithioacetals has resulted in the discovery of several useful transformations. This review summarizes recent advances in the synthetic applications of dithioacetals, with particular emphasis focused on the use of dithioacetals as zwitterion synthetic equivalents.

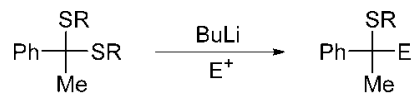

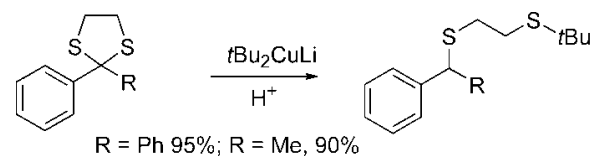

\section{Allylic Dithioacetal as a Propene 1,3- Zwitterion Equivalent}

Regioselective replacement of a carbon-heteroatom bond in an unsymmetrical allylic system by a carbon-carbon bond is important in organic synthesis. The $\alpha$ - or $\gamma$ selectivity depends on the natures of the substrates, reagents (or catalysts), stoichiometry, and reaction conditions. ${ }^{[28]} \mathrm{Al}-$ lylic dithioacetal has been shown to be unique in undergoing regioselective geminal dimethylation upon treatment with $\mathrm{MeMgI}$ in the presence of $\mathrm{NiCl}_{2}$ (dppe) [Equation (10)] ${ }^{[29,30]}$ It is noteworthy that bidentate ligands such as dppe are essential in these reactions, to facilitate the re- 
ductive elimination process. ${ }^{[31]}$ Quaternary carbon can thus be obtained in good yield.

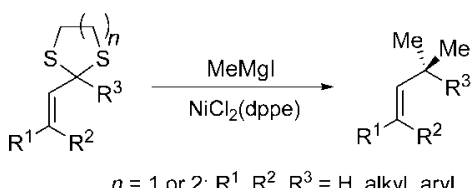

When 1 is allowed to react with $\mathrm{Bu}_{2} \mathrm{CuLi}$ [Equation (11)], allyl anion $\mathbf{2}$ is expected. Treatment of $\mathbf{2}$ with a range of electrophiles gives the corresponding $E / Z$ mixtures of vinyl sulfides 3 in good yields. Through the use of the WenkertTakei procedure, ${ }^{[2]}$ the vinylic carbon-sulfur bond is displaced by the corresponding carbon-carbon bond, giving 4 [Equation (11)]. In general, a Grignard reagent possessing the same alkyl group as the $\mathrm{R}^{2}$ group in $\mathbf{2}$ is used, so that the stereochemical problem in $\mathbf{4}$ is circumvented. Representative examples are shown in Table 1. The reaction can be regarded as the use of allylic dithioacetal as a propene-1,3 zwitterion synthon. ${ }^{[32]}$

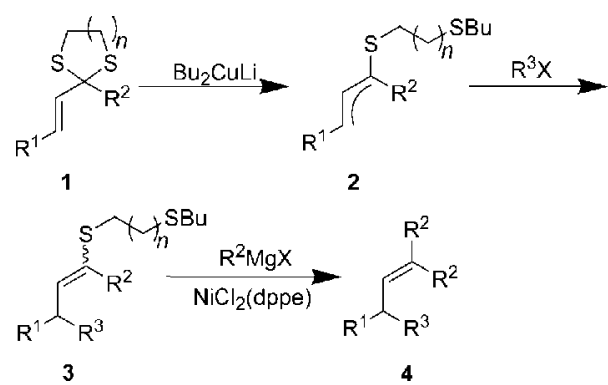

Table 1. Treatment of $\mathbf{2}$ with $\mathrm{Bu}_{2} \mathrm{CuLi}$ and $\mathrm{R}^{3} \mathrm{X}$, followed by $\mathrm{NiCl}_{2}$ (dppe)-catalyzed cross coupling with $\mathrm{R}^{2} \mathrm{MgX}$.

\begin{tabular}{ccccc}
\hline $\mathrm{R}^{1}$ & $\mathrm{R}^{2}$ & $\mathrm{R}^{3} \mathrm{X}$ & $\begin{array}{c}\text { Yield }(\%) \text { of } \mathbf{3} \\
(E / Z)\end{array}$ & $\begin{array}{c}\text { Yield }(\%) \\
\text { of } \mathbf{4}\end{array}$ \\
\hline $\mathrm{Ph}$ & $\mathrm{Me}$ & $\mathrm{MeI}$ & $79(1: 1)$ & 83 \\
$\mathrm{Ph}$ & $\mathrm{Me}$ & $\mathrm{TMSCH}_{2} \mathrm{Cl}$ & $74(E$ only $)$ & 84 \\
2-Naph & $\mathrm{Me}$ & $\mathrm{BuBr}$ & $80(1: 1)$ & 85 \\
2-Naph & $\mathrm{Me}$ & $\mathrm{BnBr}$ & $70(4: 3)$ & 76 \\
2-Naph & $\mathrm{Et}$ & $\mathrm{TMSCH}_{2} \mathrm{Cl}$ & $85(1: 3)$ & 85 \\
2-Naph & $\mathrm{Bu}$ & $\mathrm{TMSCH}_{2} \mathrm{Cl}$ & $88(1: 3)$ & 87 \\
\hline
\end{tabular}

The reaction can also proceed in one-pot fashion. Treatment of 5 with $\mathrm{BuLi}$ at $-78{ }^{\circ} \mathrm{C}$, followed by $(i \mathrm{PrO}) \mathrm{Me}_{2}-$ $\mathrm{SiCH}_{2} \mathrm{Cl}$, for example, gave the corresponding alkylation
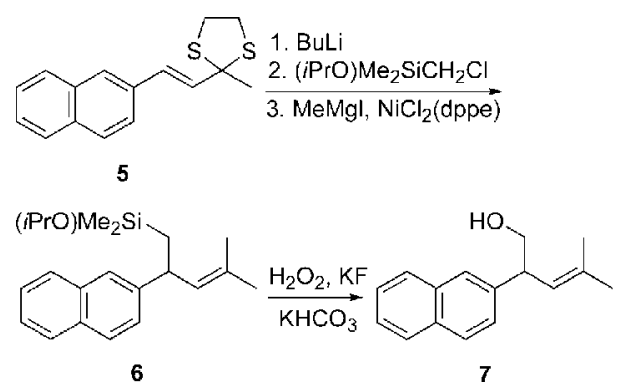

product, which was allowed to react with $\mathrm{MeMgI}$ in the presence of $\mathrm{NiCl}_{2}$ (dppe) to yield the organosilicon product 6 [Equation (12)]. Without further purification, the crude 6 was oxidized under Tamao conditions to afford the corresponding alcohol 7 in $44 \%$ overall yield.

\section{Treatment of Propargylic Dithioacetals with BuLi and Electrophiles}

Like allylic dithioacetals $\mathbf{1}$, propargylic dithioacetals 8 can serve as allene-1,3-dication synthons $\mathbf{1 0}$ upon treatment with Grignard reagents in the presence of a nickel catalyst to give 9 [Equation (13)]. ${ }^{[33]}$

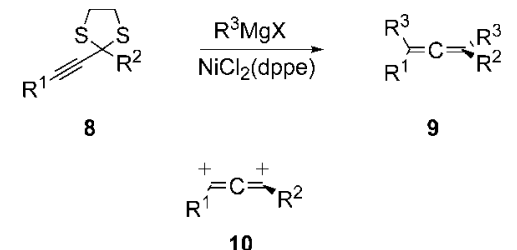

\subsection{Proton as the Electrophile}

Alternatively, treatment of $\mathbf{8}$ with an organocopper or lithium reagent at $-78{ }^{\circ} \mathrm{C}$ yields the corresponding allenyl 11 or propargyl metallic compound 12 (Scheme 2). When the mixture is quenched with $\mathrm{MeOH}$ at $-78^{\circ} \mathrm{C}$ the corresponding allenyl thioether $\mathbf{1 3}$ is obtained in excellent yield. Representative examples are shown in Table 2. ${ }^{[27,34]}$ Other hard electrophiles such as $\mathrm{TMSCl}$ or $\mathrm{Bu}_{3} \mathrm{SnCl}$ also afford the corresponding allenes $\mathbf{1 3}$ in good to excellent yield.

Table 2. Treatment of $\mathbf{8}$ with $\mathrm{R}^{3}{ }_{2} \mathrm{CuLi}$, followed by protonation.

\begin{tabular}{ccccc}
\hline $\mathrm{R}^{1}$ & $\mathrm{R}^{2}$ & $\mathrm{R}^{3}$ & Electrophile & Yield $(\%)$ of $\mathbf{1 3}$ \\
\hline $\mathrm{Ph}$ & $\mathrm{Me}$ & $t \mathrm{Bu}$ & $\mathrm{MeOH}$ & 88 \\
$\mathrm{Ph}$ & $\mathrm{Ph}$ & $t \mathrm{Bu}$ & $\mathrm{MeOH}$ & 95 \\
$\mathrm{Ph}$ & $\mathrm{Ph}$ & $n \mathrm{Bu}$ & $\mathrm{MeOH}$ & 93 \\
$n \mathrm{Bu}$ & $\mathrm{Me}$ & $t \mathrm{Bu}$ & $\mathrm{MeOH}$ & 82 \\
$\mathrm{H}$ & $\mathrm{Ph}$ & $n \mathrm{Bu}$ & $\mathrm{MeOH}$ & 82 \\
$\mathrm{Ph}$ & $\mathrm{Ph}$ & $n \mathrm{Bu}$ & $\mathrm{TMSCl}$ & $94^{[\mathrm{a}]}$ \\
$\mathrm{Ph}$ & $\mathrm{Ph}$ & $n \mathrm{Bu}$ & $n \mathrm{Bu}_{3} \mathrm{SnCl}$ & $81^{[\mathrm{b}]}$ \\
\hline
\end{tabular}

[a] $\mathrm{TMS}(\mathrm{Ph}) \mathrm{C}=\mathrm{C}=\mathrm{CPh}\left(\mathrm{SCH}_{2} \mathrm{CH}_{2} \mathrm{SBu}\right)$ is obtained. [b] $\mathrm{Bu}_{3} \mathrm{Sn}(\mathrm{Ph})$ $\mathrm{C}=\mathrm{C}=\mathrm{CPh}\left(\mathrm{SCH}_{2} \mathrm{CH}_{2} \mathrm{SBu}\right)$ is obtained.

\subsection{Reaction with Soft Electrophiles}

On the other hand, when soft electrophiles such as alkyl halides are employed, alkynes $\mathbf{1 4}$ are obtained exclusively (Scheme 2). ${ }^{[27,34]}$ Representative examples are summarized in Table 3. 

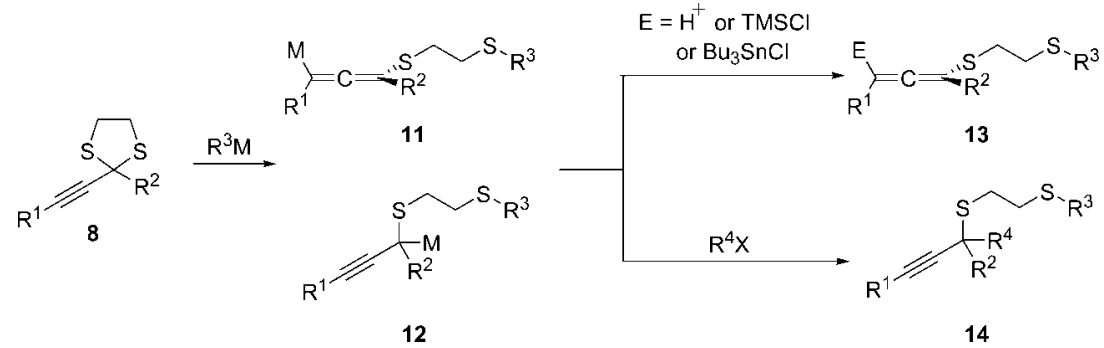

Scheme 2

Table 3. Treatment of $\mathbf{8}$ with $\mathrm{R}_{2}^{3} \mathrm{CuLi}$, followed by alkyl halides.

\begin{tabular}{ccccc}
\hline $\mathrm{R}^{1}$ & $\mathrm{R}^{2}$ & $\mathrm{R}^{3}$ & $\mathrm{R}^{4} \mathrm{X}$ & Yield $(\%)$ of $\mathbf{1 4}$ \\
\hline $\mathrm{Ph}$ & $\mathrm{Me}$ & $t \mathrm{Bu}$ & $\mathrm{MeI}$ & 81 \\
$\mathrm{Ph}$ & $\mathrm{Me}$ & $t \mathrm{Bu}$ & $\mathrm{H}_{2} \mathrm{C}=\mathrm{CHCH}_{2} \mathrm{Br}$ & 80 \\
$\mathrm{Ph}$ & $\mathrm{Ph}$ & $n \mathrm{Bu}$ & $n \mathrm{BuBr}$ & 89
\end{tabular}

\subsection{Reaction with $\mathrm{C}\left(\mathrm{sp}^{2}\right)$ Carbon Electrophiles}

As can be seen in Table 3, the reaction proceeds successfully with carbon electrophiles with $\mathrm{C}\left(\mathrm{sp}^{3}\right)$ hybridization. The reaction would be more versatile if $\mathrm{C}\left(\mathrm{sp}^{2}\right)$ carbon electrophiles could also be used. Thus, transmetallation of the organocopper intermediate with $\mathrm{ZnBr}_{2}$, followed by the palladium-catalyzed coupling reaction, gave the corresponding allenes $\mathbf{1 5}$ in good yield [Equation (14)]. Typical examples are tabulated in Table 4. ${ }^{[34]}$

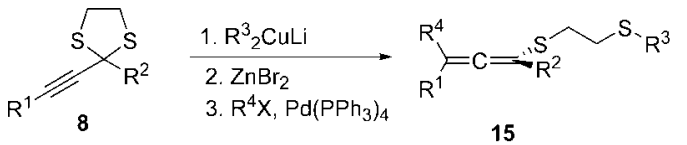

Table 4. Treatment of 8 with $\mathrm{R}_{2}^{3} \mathrm{CuLi}$ followed by $\mathrm{ZnBr}_{2}$ and subsequent coupling with electrophiles in the presence of $\mathrm{Pd}\left(\mathrm{PPh}_{3}\right)_{4}$.

\begin{tabular}{ccccc}
\hline $\mathrm{R}^{1}$ & $\mathrm{R}^{2}$ & $\mathrm{R}^{3}$ & $\mathrm{R}^{4} \mathrm{X}$ & Yield $(\%)$ of $\mathbf{1 5}$ \\
\hline $\mathrm{Ph}$ & $\mathrm{Ph}$ & $n \mathrm{Bu}$ & $4-\mathrm{MeC}_{6} \mathrm{H}_{4} \mathrm{I}$ & 69 \\
$\mathrm{Ph}$ & $\mathrm{Ph}$ & $n \mathrm{Bu}$ & $t \mathrm{BuCOCl}^{2}$ & 65 \\
$n \mathrm{Bu}$ & $\mathrm{Me}$ & $n \mathrm{Bu}$ & $4-\mathrm{MeC}_{6} \mathrm{H}_{4} \mathrm{I}$ & 78 \\
\hline
\end{tabular}

When allyl bromide is employed, the corresponding triene $\mathbf{1 7}$ is obtained exclusively [Equation (15)]. Presumably, the expected product allylallene $\mathbf{1 8}$ undergoes double bond migration under the reaction conditions. ${ }^{\left[{ }^{[4]}\right.}$

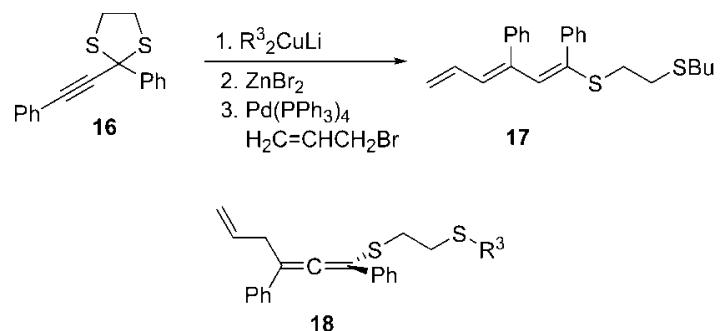

\subsection{Synthesis of Cumulenes}

It is known that a propargylic ether can readily undergo an $\mathrm{S}_{\mathrm{N}} 2^{\prime}$ reaction with an organocopper reagent to give the corresponding allene. ${ }^{[35]}$ It is highly intriguing to compare the reactivities of a propargylic ether and a propargylic dithioacetal upon treatment with an organocopper reagent. Thus, treatment of 19 with $n \mathrm{Bu}_{2} \mathrm{CuLi}$, followed by the usual workup, gives 20 in $91 \%$ yield [Equation (16)] ${ }^{[34]}$ Attempts to synthesize the higher cumulenes from $\mathbf{2 1}$ or $\mathbf{2 2}$ were unsuccessful, mixtures of unidentified products being obtained. ${ }^{[34]}$

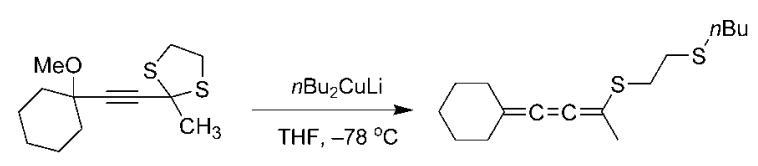

19

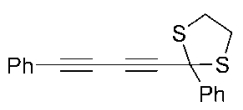

21
20

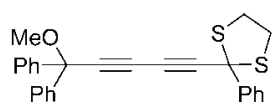

22

\section{Propargylic Dithioacetals as 3,3-Propyne Zwitterion Equivalents}

Direct coupling of a 1,1-zwitterion synthon with another kind of 1,1-zwitterion equivalent appears to be an attractive route for the synthesis of carbon-carbon double bonds. As described in Scheme 1, dithioacetals can be olefinated through treatment with Grignard reagents in the presence of catalytic amounts of $\mathrm{NiCl}_{2}\left(\mathrm{PPh}_{3}\right)_{2}{ }^{[19-22,36]}$ The major limitation of this reaction is the use of Grignard reagents: substrates containing carbonyl or cyano groups, terminal alkynes, etc. cannot be used under the reaction conditions.

$\alpha$-Bromoacetates and related compounds are known to serve as 1,1-zwitterion equivalents in, for example, Darzens reactions to form epoxides with carbonyl compounds. ${ }^{[37]}$ It is envisaged that the thioether moiety in $\mathbf{1 4}$ may serve as a leaving group such that functionalized olefins $\mathbf{2 4}$ might be obtained when such functionalized alkyl halides are used in the reaction shown in Equation (17). ${ }^{[38]}$ It is interesting to note that ester group in $\mathbf{2 3}$ is stable under the reaction conditions. 


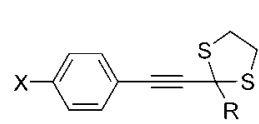

23
24

$\mathrm{X}=\mathrm{H}, \mathrm{R}=\mathrm{Ph} 71 \%$

$\mathrm{X}=\mathrm{CO}_{2} \mathrm{Et}, \mathrm{R}=\mathrm{Bu} 63 \%$

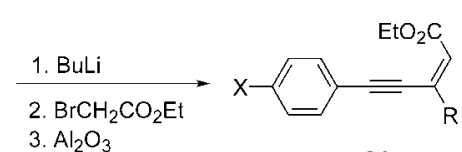

Dithioacetals of benzophenone $\mathbf{2 5}$ and fluorenone $\mathbf{2 6}$ yield similar olefination products 27 and $\mathbf{2 8}$, respectively, when functionalized methyl halides are employed.

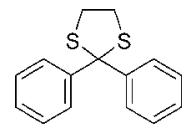

25

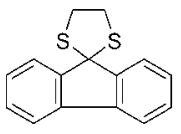

26

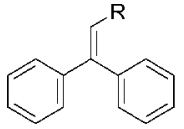

$27 \mathrm{R}=\mathrm{COPh}$ or $\mathrm{NO}_{2}$

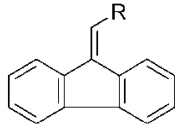

$28 \mathrm{R}=\mathrm{COPh}$ or $\mathrm{CN}$

\section{Propargylic Dithioacetals as 1,3-Propyne Zwitterion Equivalents}

As shown in Scheme 2, the regioselectivity of the reactions of sulfur-substituted allenyl $\mathbf{1 1}$ or propargyl anion $\mathbf{1 2}$ strongly depends on the nature of the electrophiles. As can be seen from Tables 2-4, a number of allenyl thioethers 13 and propargylic thioethers $\mathbf{1 4}$ can easily be obtained by treatment of $\mathbf{8}$ with organocopper reagents. Subsequent treatment of these thioethers with Grignard reagents in the presence of $5 \mathrm{~mol}-\%$ of $\mathrm{NiCl}_{2}(\mathrm{dppf})$ resulted in a convenient synthesis of substituted allenes $\mathbf{2 9}$ or $\mathbf{3 0}$ [Equation (18) and Equation (19)]. Table 5 summarizes representative examples. The overall reaction can be regarded as the use of propargylic dithioacetals as allene-1,3-zwitterion equivalents 31 or 32. ${ }^{[27,34]}$

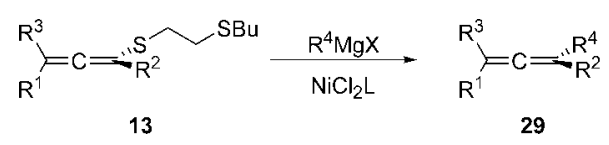

$$
\begin{aligned}
& \overbrace{\mathrm{R}^{1}} \overbrace{\mathrm{R}^{2}}^{\mathrm{R}^{\mathrm{R}^{3}}} \frac{\mathrm{R}^{4} \mathrm{MgX}}{\mathrm{NiCl}_{2} \mathrm{~L}} \underset{\mathrm{R}^{1}}{\mathrm{SBu}}=\mathrm{C}=\mathrm{R}_{\mathbf{3 0}}^{\mathrm{R}^{4}} \\
& 14 \\
& \mathrm{R}^{{ }^{-}} \stackrel{+}{=} \mathrm{R}^{2} \\
& \mathrm{R}^{\stackrel{+}{F} \mathrm{C}=}=\mathrm{R}^{2}
\end{aligned}
$$

Table $5 . \mathrm{NiCl}_{2} \mathrm{~L}$-catalyzed cross coupling reactions of $\mathbf{1 3}$ or $\mathbf{1 4}$ with Grignard reagents.

\begin{tabular}{ccccccc}
\hline $\begin{array}{c}\text { Sub- } \\
\text { strate }\end{array}$ & $\mathrm{R}^{1}$ & $\mathrm{R}^{2}$ & $\mathrm{R}^{3}$ & $\mathrm{R}^{4}$ & $\mathrm{~L}$ & $\begin{array}{c}\text { Product } \\
\text { (yield \%) }\end{array}$ \\
\hline $\mathbf{1 3}$ & $\mathrm{Ph}$ & $\mathrm{Me}$ & $\mathrm{H}$ & $\mathrm{Me}$ & $\mathrm{dppf}$ & $\mathbf{2 8}(81)$ \\
$\mathbf{1 3}$ & $n \mathrm{Bu}$ & $\mathrm{Me}$ & $\mathrm{H}$ & $\mathrm{Ph}$ & $\mathrm{dppf}$ & $\mathbf{2 8}(87)$ \\
$\mathbf{1 3}$ & $\mathrm{Ph}$ & $\mathrm{Ph}$ & $\mathrm{H}$ & $i \mathrm{Pr}$ & dppe & $\mathbf{2 8}(50)^{[\mathrm{a}]}$ \\
$\mathbf{1 4}$ & $\mathrm{Ph}$ & $\mathrm{Me}$ & $\mathrm{Me}$ & $\mathrm{TMSCH}$ & $\mathrm{dppe}$ & $\mathbf{2 9}(72)$ \\
$\mathbf{1 4}$ & $\mathrm{Ph}$ & $\mathrm{Me}$ & $\mathrm{H}_{2} \mathrm{C}=\mathrm{CHCH}_{2} n \mathrm{Bu}$ & dppe & $\mathbf{2 9}(62)$ \\
$\mathbf{1 4}$ & $\mathrm{Ph}$ & $\mathrm{Ph}$ & $n \mathrm{Bu}_{2}$ & $\mathrm{Ph}$ & dppe & $\mathbf{2 9}(67)$ \\
$\mathbf{1 5}$ & $n \mathrm{Bu}$ & $\mathrm{Me}$ & $4-\mathrm{MeC}_{6} \mathrm{H}_{4}$ & $\mathrm{Ph}$ & dppe & $\mathbf{2 8}(55)$ \\
\hline
\end{tabular}

[a] The corresponding reduction product is obtained. ${ }^{[39]}$

\section{Annulation of Propargylic Dithioacetals - Synthesis of Furans and Pyrroles}

As shown in Scheme 2, treatment of propargylic dithioacetals with butyllithium or the corresponding copper reagent may result either in allene or in alkyne products, depending on the nature of the electrophiles. The selectivity of the reaction has been carefully examined with benzaldehyde as the electrophile. It is interesting to note that the selectivity is very highly dependent on the reaction conditions. When the reaction is carried out in THF in the presence of HMPA at $-65^{\circ} \mathrm{C}$, allene 33 is obtained almost exclusively. On the other hand, when the solvent is changed to ether at $-100{ }^{\circ} \mathrm{C}$ in the absence of HMPA, propargylic carbinol 34 becomes the major product [Equation (20)]. Representative results are shown in Table 6. ${ }^{[40]}$

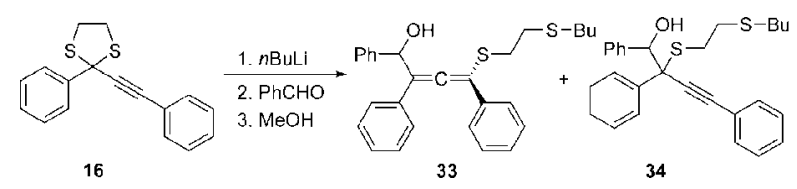

Table 6. Selectivity in the reaction of $\mathbf{1 6}\left(\mathrm{R}^{1}=\mathrm{R}^{2}=\mathrm{Ph}\right)$ with $n \mathrm{BuLi}$ and then with benzaldehyde.

\begin{tabular}{cccc}
\hline Solvent & $\begin{array}{l}\text { HMPA } \\
\text { (equiv.) }\end{array}$ & $T\left[{ }^{\circ} \mathrm{C}\right]$ & $\mathbf{3 3 / 3 4}$ \\
\hline THF & 0 & -65 & $83: 17$ \\
THF & 10 & -65 & $99: 1$ \\
Ether & 10 & -65 & $95: 5$ \\
Ether & 0 & -65 & $20: 80$ \\
Ether & 0 & -100 & $3: 97$ \\
\hline
\end{tabular}




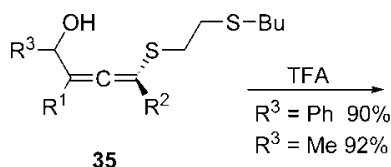

$\mathrm{R}^{\mathrm{R}^{3}} \mathrm{O}^{\mathrm{R}}$

36

Table 7. One-pot synthesis of trisubstituted furans $36\left(\mathrm{R}^{2}=\mathrm{Ph}\right)$ from 8.

\begin{tabular}{ccc}
\hline $\mathrm{R}^{1}$ & $\mathrm{R}^{3}$ & Yield (\%) \\
\hline $\mathrm{Ph}$ & $\mathrm{Ph}$ & 60 \\
$n \mathrm{Bu}$ & $\mathrm{Et}$ & 40 \\
$\mathrm{Ph}$ & $\mathrm{Ph}$ & 73 \\
$n \mathrm{Bu}$ & $\mathrm{H}_{2} \mathrm{C}=\mathrm{CHC}_{6} \mathrm{H}_{4}$ & 42 \\
$\mathrm{Ph}$ & $\mathrm{F}_{3} \mathrm{CC}_{6} \mathrm{H}_{4}$ & 42 \\
$\mathrm{Ph}$ & $\mathrm{MeO}_{2} \mathrm{C} \mathrm{C}_{6} \mathrm{H}_{4}$ & 45 \\
$\mathrm{Ph}$ & $\mathrm{NCC}_{6} \mathrm{H}_{4}$ & 37 \\
$\mathrm{Ph}$ & $\mathrm{MeOC}_{6} \mathrm{H}_{4}$ & 62 \\
$\mathrm{Ph}$ & 2 -furyl & 66 \\
\hline
\end{tabular}

Pyrroles 37 are also obtained in a similar manner when imines are used in place of aldehydes [Equation (22)]. It is noteworthy that $\mathrm{BF}_{3} \cdot \mathrm{OEt}_{2}$ appeared to be a better Lewis catalyst for the cyclization in pyrrole synthesis. ${ }^{[41]}$ Typical examples are outlined in Table 8.

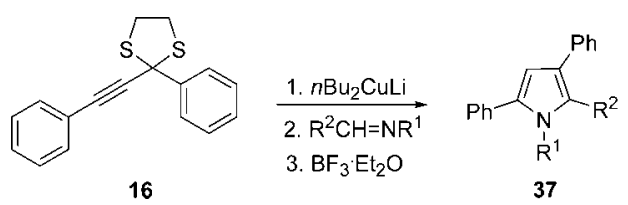

Table 8. Synthesis of substituted pyrroles 37 .

\begin{tabular}{ccc}
\hline $\mathrm{R}^{1}$ & $\mathrm{R}^{2}$ & Yield (\%) \\
\hline$n \mathrm{Bu}$ & $\mathrm{Ph}$ & 62 \\
$\mathrm{Me}$ & $\mathrm{Ph}$ & 64 \\
$\mathrm{Ph}$ & $\mathrm{Ph}$ & 73 \\
$n \mathrm{Bu}$ & 2-thienyl & 63 \\
$n \mathrm{Bu}$ & 2-furyl & 71
\end{tabular}

As shown in Tables 7 and 8, the strategy provides a useful route for the synthesis of teraryls with furan or pyrrole rings in the middle. In addition, the reaction is particularly promising for the introduction of substituents at $\mathrm{C}_{3}$ in furans or pyrroles. More importantly, this substituent can be a long-chain aliphatic moiety, as it is a common strategy to include such alkyl groups to increase the solubility for convenience of processing, to provide devices for optoelectronic investigations. Accordingly, this procedure indeed furnishes a very convenient approach for the synthesis of oligoaryls containing these heterocycles.

Oligoaryls 41 with two furan or pyrrole moieties can be obtained in one-pot fashion from $\mathbf{3 8}$ by starting from dial- dehyde 39 or diimine 40 [Equation (23), Table 9]. The use of these materials as efficient non-amine-based hole-transporting materials in electroluminescent devices has been reported. ${ }^{[42]}$

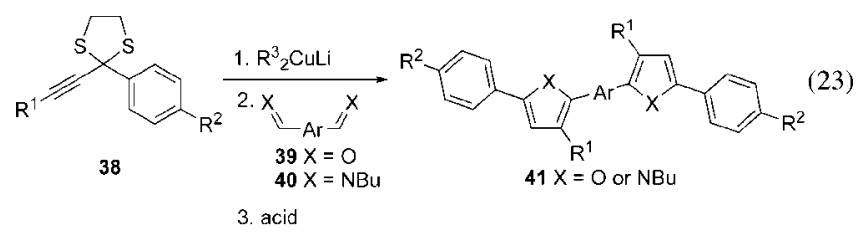

Table 9. Synthesis of penta- and hexaaryls $\mathbf{4 1}$.

\begin{tabular}{ccccc}
\hline$-\mathrm{Ar}-$ & $\mathrm{R}^{1}$ & $\mathrm{R}^{2}$ & $\mathrm{X}$ & Yield (\%) \\
\hline$-\mathrm{C}_{6} \mathrm{H}_{4-}$ & $n \mathrm{Bu}$ & $\mathrm{H}$ & $\mathrm{O}$ & 40 \\
$-\mathrm{C}_{6} \mathrm{H}_{4}-$ & $n \mathrm{Bu}$ & $\mathrm{H}_{2} \mathrm{C}=\mathrm{CH}-$ & $\mathrm{O}$ & 51 \\
$-\mathrm{C}_{6} \mathrm{H}_{4} \mathrm{C}_{6} \mathrm{H}_{4-}$ & $n \mathrm{Bu}$ & $\mathrm{H}$ & $\mathrm{O}$ & 59 \\
$-\mathrm{C}_{6} \mathrm{H}_{4} \mathrm{C}_{6} \mathrm{H}_{4-}$ & $n \mathrm{Bu}$ & $\mathrm{H}_{2} \mathrm{C}=\mathrm{CH}-$ & $\mathrm{O}$ & 72 \\
$-\mathrm{C}_{6} \mathrm{H}_{4} \mathrm{C}_{6} \mathrm{H}_{4-}$ & $n \mathrm{Bu}$ & $\mathrm{TMSC} \equiv \mathrm{C}-$ & $\mathrm{O}$ & 56 \\
$-\mathrm{C}_{6} \mathrm{H}_{4}-$ & $\mathrm{Ph}$ & $\mathrm{H}$ & $\mathrm{N} n \mathrm{Bu}$ & 28 \\
\hline
\end{tabular}

\section{Bidirectional Iterative Synthesis of Furan- Containing Oligoaryls}

As described in the previous section, the annulation procedure furnishes a convenient synthesis of 2,3,5-trisubstituted furans from the corresponding dithioacetals. Thermally and photochemically stable pentaaryls containing alternating benzene and furan moieties can also be obtained by this approach. It is important to note that the presence of an alkyl substituent at the C-3 position of the furan heterocycle may increase the solubility of these oligoaryls in organic solvents. In addition, as shown in Table 7, a variety of functional groups, including the ester moiety, are stable under the reaction conditions. Thus, diester $\mathbf{4 2}$ is obtained in $45 \%$ yield by the same procedure as described in Equation (23). Dialdehyde 43, obtained by functional group transformation, is employed for the next annulation reaction with $\mathbf{4 4}$ to afford the corresponding nonaaryl $\mathbf{4 5}$ in $38 \%$ yield. In a similar manner, 13-mer $\mathbf{4 7}$ is obtained in $32 \%$ yield from dialdehyde 46 and 44 (Scheme 3). Because of the presence of the butyl groups, the solubility of $\mathbf{4 7}$ in organic solvents is very good. These oligomers can also easily be precipitated by adding methanol to the organic solutions. Since $\mathbf{4 7}$ contains two ester groups on the terminal phenyl rings, further transformation by repeating the same procedures would provide higher homologues of alternating benzene-furan molecular wires. ${ }^{[43]}$

A pyrrole moiety can also be introduced into the oligoaryl system if an imine is employed as an electrophile. Thus, treatment of diimine $\mathbf{4 9}$ with propargylic dithioacetal 48, followed by treatment with $\mathrm{BF}_{3} \cdot \mathrm{OEt}_{2}$, afforded $\mathbf{5 0}$ in $47 \%$ yield [Equation (24)]. ${ }^{[43]}$

The general criterion for the synthesis of conjugated oligoaryls requires the use of a dialdehyde or a diimine for the 

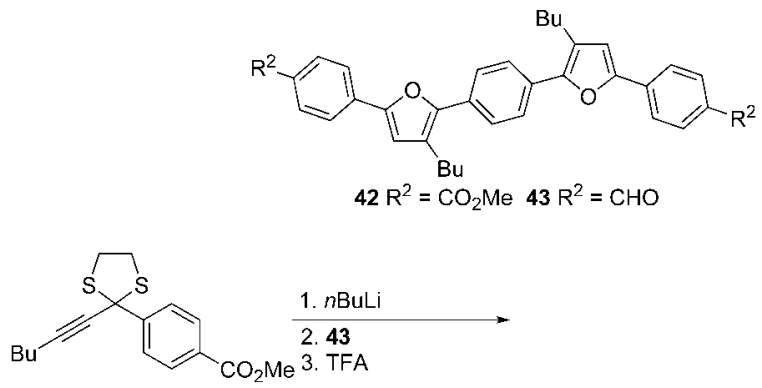

44

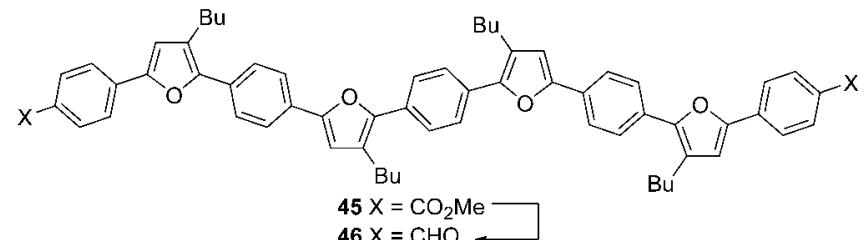

$44 \stackrel{\text { 1. } n \mathrm{BuLi}}{\stackrel{\text { 2. } 46}{\text { 3. TFA }}}$

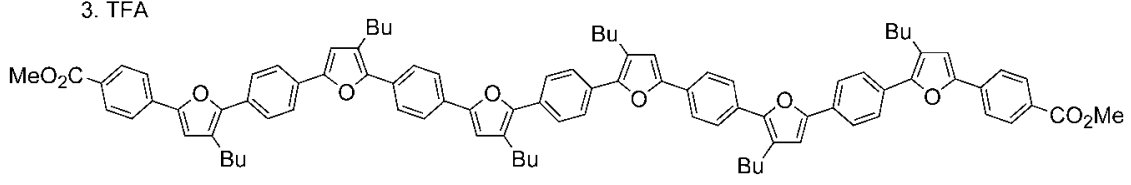

47

Scheme 3.

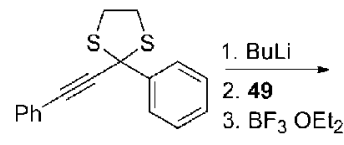

48<smiles>Brc1ccccc1-c1ccc(-c2ccc(-c3cc(-c4cc(-c5ccccc5)cc(-c5ccccc5)c4-c4ccccc4)ccc3-c3ccccc3)o2)cc1</smiles><smiles>Brc1cc(-c2ccccc2)oc1-c1ccc(-c2oc(-c3ccc(C=Nc4ccccc4)cc3)cc2Br)cc1</smiles>

annulation step. Thus, both silole- and phosphole-containing dialdehydes $\mathbf{5 1}$ and $\mathbf{5 2}$ are used for the synthesis of $\mathbf{5 3}$ and $\mathbf{5 4}$ in satisfactory yields. ${ }^{[4,45]}$

\section{Combinations of Heck and Sonogashira Reactions with Annulation}

As described in the previous section, the key to success in the bidirectional iterative synthesis of furan-containing<smiles>C[Si]1(C)C(c2ccc(C=O)cc2)=C(c2ccccc2)C(c2ccccc2)=C1c1ccc(C=O)cc1</smiles>

51

52<smiles>C[Si]1(C)C(c2ccc(-c3oc(-c4ccccc4)cc3-c3ccccc3)cc2)=C(c2ccccc2)C(c2ccccc2)=C1c1ccc(-c2oc(-c3ccccc3)cc2-c2ccccc2)cc1</smiles>

53<smiles></smiles>

54

oligoaryls requires the use of a dialdehyde moiety as an electrophile. As shown in Tables 7 and 9, double and triple bonds are stable under the reaction conditions. Accordingly, elongation of conjugation lengths can be achieved by means of Heck or Sonogashira reactions. The presence of an aldehyde group in aryl halides can convert these olefinic or alkynyl substituents into the corresponding electrophiles, 


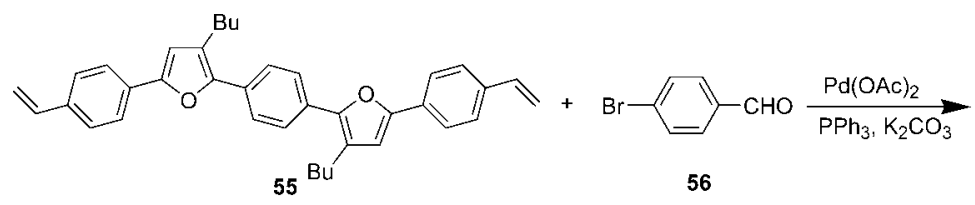<smiles>O=Cc1ccc(/C=C/c2ccc(-c3cc(Br)c(-c4ccc(-c5oc(-c6ccc(/C=C/c7ccc(C=O)cc7)cc6)cc5Br)cc4)o3)cc2)cc1</smiles>

57<smiles></smiles>

59<smiles>C=Cc1ccc(C=CC#CC2(C=C)SCCS2)cc1</smiles>

58

Scheme 4.<smiles></smiles><smiles>O=Cc1ccc(C#Cc2ccc(-c3ccc(-c4ccc(-c5oc(-c6ccc(C#Cc7ccc(C=O)cc7)cc6)cc5Br)cc4)o3)cc2)cc1</smiles>

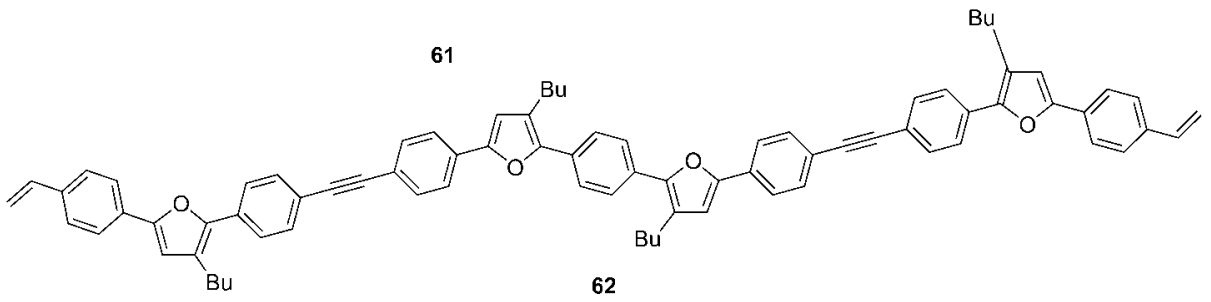

Scheme 5 .

which can then undergo further annulation procedures to generate furan moieties. Thus, treatment of $\mathbf{5 5}$ with 4-bromobenzaldehyde (56) under Heck conditions yields 57, which is annulated with $\mathbf{5 8}$ to give $\mathbf{5 9}$ in $45 \%$ overall yield (Scheme 4). ${ }^{[41,46]}$

Similarly, the $\mathrm{PdCl}_{2}\left(\mathrm{PPh}_{3}\right)_{2}$-CuI-catalyzed reaction between 60 and 56 affords 61, which proceeds in a reaction with propargylic dithioacetals $\mathbf{5 8}$ and butyllithium to produce $\mathbf{6 2}$ in $40 \%$ yield (Scheme 5). ${ }^{[43,46]}$

\section{Convergent Synthesis}

Since an ester group is stable under the annulation conditions, allenyllithium intermediate $\mathbf{4 4}$, generated from the

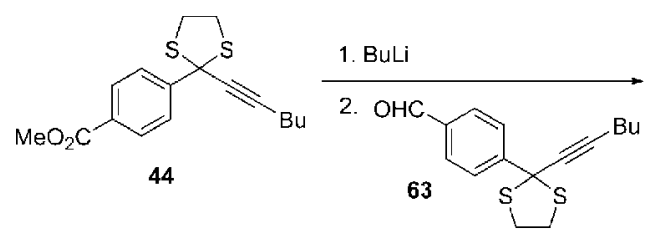

3. TFA<smiles>CC#CC1(c2ccc(-c3ccc(-c4ccc(OC)cc4)o3)cc2)SCCS1</smiles> 


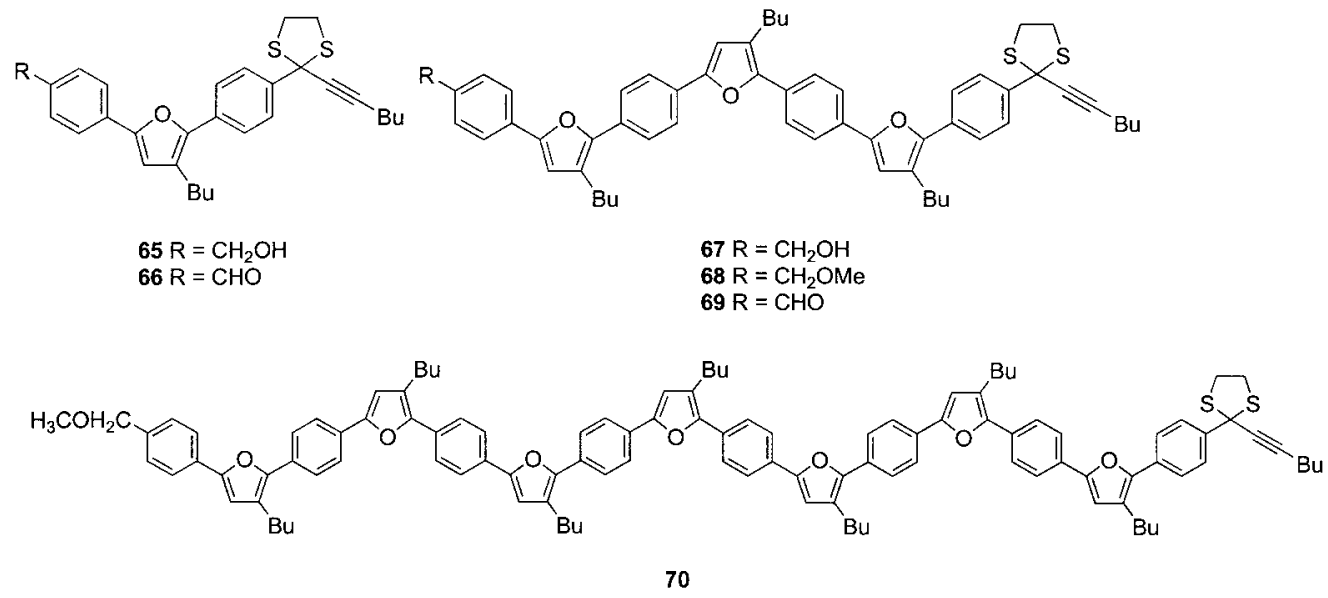

corresponding propargylic dithioacetal bearing an ester substituent, reacts with another molecule of aldehyde 63, also bearing a propargylic dithioacetal moiety as the substituent, to afford 64 [Equation (25)]. ${ }^{[47]}$

Since the ester group can easily be converted into an aldehyde, this procedure can be used in the convergent synthesis of alternating benzene-furan oligoaryls. Thus, treatment of $\mathbf{6 5}$ with $\mathbf{6 6}$ under typical annulation conditions gives the corresponding heptaaryls $\mathbf{6 7}$ in $73 \%$ yield. It is interesting to note that free hydroxy groups can be used without protection (extra equivalents of BuLi are required, of course). Further treatment of the methyl ether $\mathbf{6 8}$ with aldehyde 69 affords $15-$ mer 70 in $73 \%$ yield.

\section{Furan-Containing Oligoaryl Cyclophanenes}

Cyclophanes have provided useful models for the investigation of through-space interactions between chromophores. ${ }^{[48]}$ The presence of five-membered heteroaromatic ring(s) in cyclophanes may produce unique structural features, because the stereochemistries of these molecules are very different from those of cyclophanes made up only of para-substituted benzene derivatives. ${ }^{[49]}$ Furan-containing oligoaryl cyclophane $\mathbf{7 1}$ and cyclophanene $\mathbf{7 2}$ are synthesized from propargylic dithioacetal 44. Treatment of $\mathbf{4 4}$ with $\mathrm{BuLi}$, and then with dialdehyde $\mathbf{7 3}$ followed by trifluoroacetic acid, afforded $\mathbf{7 4}$ in $65 \%$ yield. Reduction of 74 with $i \mathrm{Bu}_{2} \mathrm{AlH}$ then gave the alcohol, which was further converted into bromide $\mathbf{7 5}$ in $93 \%$ yield. Cyclophane $\mathbf{7 1}$ was obtained in $76 \%$ yield by treatment of $\mathbf{7 5}$ with $\mathrm{PhLi}$ (Scheme 6). ${ }^{[50]}$

Cyclization of 75 with $\mathrm{Na}_{2} \mathrm{~S} \cdot 9 \mathrm{H}_{2} \mathrm{O}$ gave $\mathbf{7 6}$ in $61 \%$ yield. Exposure of 76 to $i \operatorname{Pr}_{2} \mathrm{NLi}$ at $0{ }^{\circ} \mathrm{C}$, followed by trapping of the intermediate with MeI, afforded 77 in $94 \%$ yield. The formation of the double bond was achieved by treatment of 77 with Meerwein reagent followed by $t \mathrm{BuOK}$, to give $\mathbf{7 2}$ in $51 \%$ yield (Scheme 7). ${ }^{[50]}$

\section{Miscellaneous Reactions}

A ketone can also be used as an electrophile to facilitate the annulation of the propargylic dithioacetal. Since the ketone lacks the hydrogen at the carbonyl carbon, dihydrofuran derivative with an exocyclic double bond $\mathbf{6 5}$ is obtained in satisfactory yield [Equation (26)]. ${ }^{[51]}$

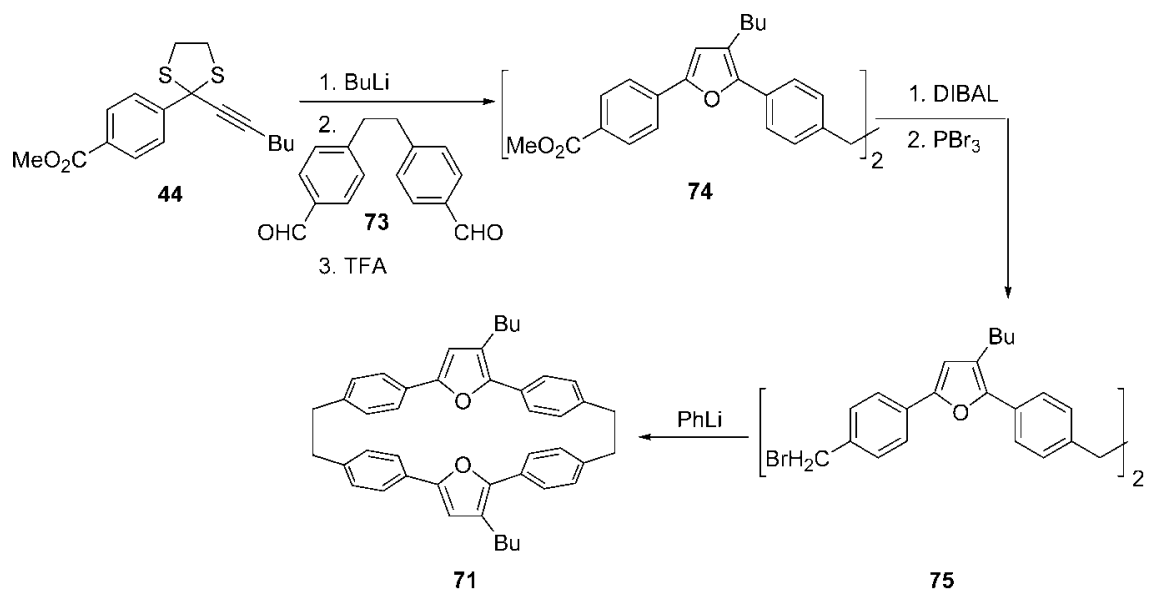

Scheme 6. 


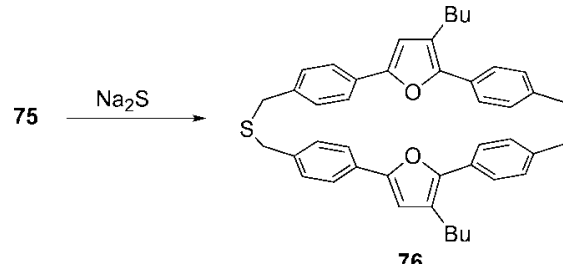

76

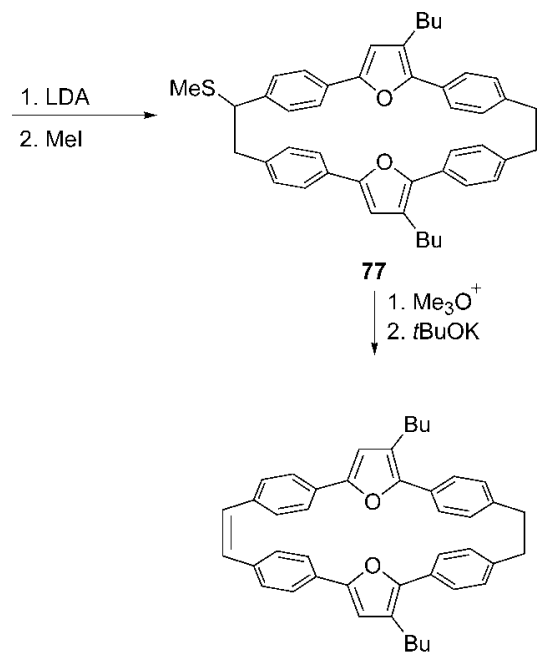

72

Scheme 7.

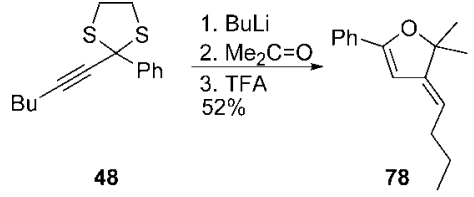

Butenolides represent core units in many natural products and exhibit a wide range of biological activities. ${ }^{[52]}$ Annulation of 2,3-allenecarboxylic acid derivatives to form butenolides are catalyzed by Lewis acids or transition metals. ${ }^{[53]}$ Accordingly, propargylic dithioacetal is sequentially treated with $\mathrm{BuLi}$, carbon dioxide gas, and then TFA to give the corresponding butenolides 79 in moderate yield [Equation (27)]. ${ }^{[51,54]}$

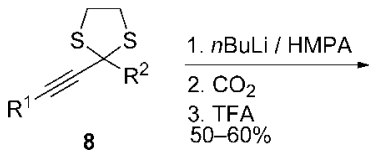

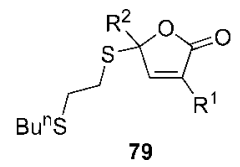

If the TFA is replaced by methyl iodide, the corresponding methyl ester $\mathbf{8 0}$ is obtained in satisfactory yield [Equation (28)]. ${ }^{[54]}$

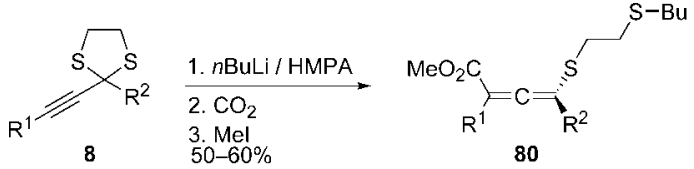

Polymeric organomercury compound $\mathbf{8 1}$ (as revealed by its $\mathrm{X}$-ray structure) is obtained in $70 \%$ yield when $\mathbf{8 0}$ is treated with $\mathrm{HgCl}_{2} / \mathrm{HgO}$ [Equation (29)]. ${ }^{[54]}$ Compound $\mathbf{8 1}$ readily undergoes a variety of cross-coupling reactions to give, for example, $\mathbf{8 2}$ stereoselectively and in good yield upon treatment with methyl vinyl ketone in the presence of $\mathrm{PdCl}_{2} \cdot{ }^{[55]}$ The overall reaction can be regarded as the use of propargylic dithioacetals as the enone dianion synthetic equivalent 83.
80

$$
\underset{\text { acetone } / \mathrm{H}_{2} \mathrm{O}}{\stackrel{\mathrm{HgCl}_{2}}{\mathrm{O}} \mathrm{HgO}}
$$<smiles>COC(=O)/C(=C(\Cl)C(=O)c1ccccc1)c1ccccc1</smiles><smiles>COC(=O)C(=C(C=CC(C)=O)C(=O)c1ccccc1)c1ccccc1</smiles>

\section{Conclusions}

In their reactions with thiophilic organolithium or organocopper reagents, propargylic dithioacetals and related compounds clearly demonstrate new types of synthetic transformations. Not only can the carbon-sulfur bonds in dithioacetals be readily displaced by carbon-carbon and/or carbon-heteroatom bonds, but a range of reactions involving polarity inversion in neighboring carbon atoms can also take place. These reactions represent useful new synthetic applications of the dithioacetal functionality. Mechanistic insight into these reactions may pave the way to allow predictions of other opportunities for new reactions. Such prospects in the rich field of organosulfur chemistry provide major incentives for continuing investigation of new methodologies starting from dithioacetals. The scope for new discoveries emanating from this research is considerable. 
[1] R. J. Cremlyn, An Introduction to Organosulfur Chemistry, Wiley, Chichester, 1996.

[2] H. Okamura, M. Miura, H. Takei, Tetrahedron Lett. 1979, 20, 43-46; E. Wenkert, T. W. Ferreira, E. L. Michelotti, J. Chem. Soc., Chem. Commun. 1979, 637-638.

[3] T.-Y. Luh, Synthesis 1990, 89-103.

[4] F. Naso, Pure Appl. Chem. 1988, 60, 79-88; V. Fiandanese, Pure Appl. Chem. 1990, 62, 1987-1992.

[5] A. Schönberg, E. Singer, E. Frese, K. Praefcke, Chem. Ber. 1965, 98, 3311-3317; W. Ried, H. Klug, Chem. Ber. 1961, 94, 368-373.

[6] F. G. Bordwell, H. M. Anderson, B. M. Pitt, J. Am. Chem. Soc. 1954, 76, 1082-1085; M. Morton, R. F. Kammereck, J. Am. Chem. Soc. 1970, 92, 3217-3218.

[7] D. C. Dittmer, P. L.-F. Chang, F. A. Davis, I. K. Stamos, K. Takahashi, J. Org. Chem. 1972, 37, 1116-1121.

[8] P. G. Gassman, D. P. Gilbert, T.-Y. Luh, J. Org. Chem. 1977, $42,1340-1344$.

[9] J. F. Biellmann, J. B. Ducep, J. L. Schmitt, J. J. Vicens, Tetrahedron 1976, 32, 1061-1064.

[10] M. P. L. Caton, D. H. Jones, R. Slack, K. R. H. Wooldridge, J. Chem. Soc. 1964, 446-451.

[11] T. Mase, K. Murase, Heterocycles 1984, 22, 1013-1015.

[12] B. Hill, M. De Vleeschauwer, K. Houde, M. Belley, Synlett 1998, 407-410.

[13] R. G. Micetich, Can. J. Chem. 1970, 48, 2006-2015.

[14] D. E. L. Carrington, K. Clarke, R. M. Scrowston, J. Chem. Soc., C 1971, 3903-3906.

[15] A. L. Braga, J. V. Comasseto, N. Petragnani, Tetrahedron Lett. 1984, 25, 1111-1114.

[16] T. W. Greene, P. G. M. Wuts, Protective Groups in Organic Synthesis $3^{\text {rd }}$ Ed., Wiley, New York, 1999.

[17] H. Hauptmann, W. F. Walter, Chem. Rev. 1962, 62, 347-404.

[18] P. C. B. Page, M. B. van Niel, J. C. Prodger, Tetrahedron 1989, 45, 7643-7677.

[19] T.-Y. Luh, Acc. Chem. Res. 1991, 24, 257-263.

[20] T.-Y. Luh, Pure Appl. Chem. 1996, 68, 105-112; T.-Y. Luh, Synlett 1996, 201-208.

[21] T.-Y. Luh, J. Organomet. Chem. 2002, 653, 209-214.

[22] T.-Y. Luh, M.-K. Leung, K.-T. Wong, Chem. Rev. 2000, 100, 3187-3204.

[23] T. Takeda, T. Fujiwara, Rev. Heteroatom Chem. 1999, 21, 93 115.

[24] A. Schönberg, S. Nickel, Ber. Dtsch. Chem. Ges. 1931, 64, 2323-2327; A. Schönberg, D. Cernick, W. Urban, Ber. Dtsch. Chem. Ges. 1931, 64, 2577-2581; N. C. Gonnella, M. V. Lakshmikantham, M. P. Cava, Synth. Commun. 1979, 9, 17-23; S. Tanimoto, T. Oida, K. Hatanaka, T. Sugimoto, Tetrahedron Lett. 1981, 22, 655-658; S. Tanimoto, T. Oida, T. Kokubo, M. Okano, Bull. Chem. Soc. Jpn. 1982, 55, 339-340.

[25] S. R. Wilson, G. M. Georgiadis, H. N. Khatri, J. E. Bartmess, J. Am. Chem. Soc. 1980, 102, 3577-3583; S. R. Wilson, P. Caldera, M. A. Jester, J. Org. Chem. 1982, 47, 3319-3321; H. Ikehira, S. Tanimoto, T. Oida, M. Okano, J. Org. Chem. 1983, 48, 1120-1122; H. Ikehira, S. Tanimoto, T. Oida, Bull. Chem. Soc. Jpn. 1983, 56, 2537-2538; A. Ohno, K. Nakamura, M. Uohama, S. Oka, T. Yamabe, S. Nagata, Bull. Chem. Soc. Jpn. $\mathbf{1 9 7 5}, 48,3718-3722$.

[26] H. Ikehara, S. Tanimoto, T. Oida, J. Chem. Soc., Perkin Trans. 1 1984, 1223-1226; A. Krief, B. Kenda, P. Barbeaux, Tetrahedron Lett. 1991, 32, 2509-2512; T. Cohen, W. M. Daniewski, R. B. Weisenfeld, Tetrahedron Lett. 1978, 19, 4665-4668; T. Cohen, M. Bhupathy, Acc. Chem. Res. 1989, 22, 152-161.

[27] H.-R. Tseng, T.-Y. Luh, J. Org. Chem. 1997, 62, 4568-4569.

[28] J. Tsuji, Palladium Reagents and Catalysts: New Perspectives for the 21st Century, Wiley, Chichester, 2004, pp. 431-517; J. Tsuji,
Transition Metal Reagents and Catalysis: Innovations in Organic Synthesis, Wiley, Chichester, 2000, Chapters 4 and 6; Y. Yamamoto, N. Asao, Chem. Rev. 1993, 93, 2207-2293.

[29] P.-F. Yang, Z.-J. Ni, T.-Y. Luh, J. Org. Chem. 1989, 54, 22612262; Y.-L. Tzeng, P.-F. Yang, N.-W. Mei, T.-M. Yuan, C.-C. Yu, T.-Y. Luh, J. Org. Chem. 1991, 56, 5289-5293; T.-M. Yuan, T.-Y. Luh, J. Org. Chem. 1992, 57, 4550-4552; T.-M. Yuan, T.Y. Luh, Org. Syn. 1997, 74, 187-193.

[30] For a recent review of transition metal-catalyzed cross-coupling reactions with Grignard reagents, see K. Oshima, Eur. J. Org. Chem. 2004, 2081-2091.

[31] H. Kurosawa, H. Ohnishe, M. Emoto, Y. Kawasaki, S. Murai, J. Am. Chem. Soc. 1988, 110, 6272-6273.

[32] C. C. Chiang, T.-Y. Luh, Synlett 2001, 977-979.

[33] H.-R. Tseng, T.-Y. Luh, J. Org. Chem. 1996, 61, 8685-8686.

[34] H.-R. Tseng, C.-F. Lee, L.-M. Yang, T.-Y. Luh, J. Org. Chem. 1999, 64, 8582-8587.

[35] J. F. Normant, A. Alexakis, J. Organomet. Chem. 1973, 57, C99-C102.

[36] L.-F. Huang, C.-H. Huang, B. Stulgies, A. de Meijere, T.-Y. Luh, Org. Lett. 2003, 5, 4489-4491.

[37] G. Berti, Top. Stereochem. 1973, 7, 93-251.

[38] H.-Y. Tu, Y.-H. Liu, Y. Wang, T.-Y. Luh, Tetrahedron Lett. 2005, 46, 771-773; H.-Y. Tu, Y.-H. Liu, Y. Wang, T.-Y. Luh, Tetrahedron Lett. 2005, 46, 1765.

[39] E. Wenkert, J. M. Hanna, Jr., M. H. Leftin, E. L. Michelotti, K. T. Potts, D. Usifer, J. Org. Chem. 1985, 50, 1125-1126.

[40] C.-M. Chou, unpublished results.

[41] C.-F. Lee, L.-M. Yang, T.-Y. Hwu, A.-H. Feng, J.-C. Tseng, T.Y. Luh, J. Am. Chem. Soc. 2000, 122, 4992-4993.

[42] L.-Z. Zhang, C.-W. Chen, C.-F. Lee, C.-C. Wu, T.-Y. Luh, Chem. Commun. 2002, 2336-2337; C.-C. Wu, W.-Y. Hung, T.L. Liu, L.-Z. Zhang, T.-Y. Luh, J. Appl. Phys. 2003, 93, 54655471 .

[43] C.-F. Lee, C.-Y. Liu, H.-C. Song, S.-J. Luo, J.-C. Tseng, H.-H. Tso, T.-Y. Luh, Chem. Commun. 2002, 2824-2825.

[44] S.-J. Luo, unpublished results.

[45] W.-C. Chang, unpublished results.

[46] C.-Y. Liu, T.-Y. Luh, Org. Lett. 2002, 4, 4305-4307.

[47] J.-C. Tseng, W.-Q. Chen, C.-M. Chou, H.-Y. Tu, J.-H. Chen, unpublished results.

[48] a) G. C. Bazan, W. J. Oldham, Jr., R. J. Lachicotte, S. Tretiak, V. Chernyak, S. Mukamel, J. Am. Chem. Soc. 1998, 120, 9188 9204 and references cited therein; b) G. P. Bartholomew, G. C. Bazan, J. Am. Chem. Soc. 2002, 124, 5183-5196 and references cited therein.

[49] N. B. Pahor, M. Calligaris, L. Randaccio, J. Chem. Soc., Perkin Trans. 2 1978, 42-45; J. F. Haley, Jr., S. M. Rosenfeld, P. M. Keehn, J. Org. Chem. 1977, 42, 1379-1386; M. P. Cooke, Jr., J. Org. Chem. 1981, 46, 1747-1750; E. Vogel, N. Jux, J. Dörr, T. Pelster, T. Berg, H.-S. Böhm, F. Behrens, J. Lex, D. Bremm, G. Hohlneicher, Angew. Chem. 2000, 112, 1143-1147; Angew. Chem. Int. Ed. 2000, 39, 1101-1105 and references cited therein.

[50] J.-C. Tseng, H.-C. Lin, S.-L. Huang, C.-L. Lin, B.-Y. Jin, C.Y. Chen, J.-K. Yu, P.-T. Chou, T.-Y. Luh, Org. Lett. 2003, 5, 4381-4384.

[51] C.-F. Lee, unpublished results.

[52] For a review, see: Y. S. Rao, Chem. Rev. 1976, 76, 625-694.

[53] For examples: J. A. Marshall, M. A. Wolf, E. M. Wallace, J. Org. Chem. 1997, 62, 367-371; S. Ma, Pure Appl. Chem. 2004, $76,651-656$.

[54] J.-M. Hsieh, unpublished results.

[55] For palladium-catalyzed Heck-type reactions of organomercury compounds, see: R. F. Heck, J. Am. Chem. Soc. 1968, 90, $5518-5526$.

Received April 6, 2005

Published Online: July 12, 2005 